\title{
Educators' and students' perceptions of online distance education before and amid COVID-19: Key concerns and challenges
}

\author{
Tatiana Markova* \\ Ural State University of Economics, Department of Business Foreign Language, 620144 \\ Yekaterinburg, Russia
}

\begin{abstract}
This paper aims to present Russian educators' and students' perceptions of online education before and during the pandemic. The author analyses the primary research data collected by the team of USUE authors via quantitate research methods, and secondary research data. Based on the empirical sociological data the author identifies the key challenges facing educators' community - negative attitudes to online teaching and learning, lack of digital pedagogy skills and ineffective interaction practices. It is concluded that in the emergency situation teachers overall managed to fit rapid curriculum transformations. Yet, university leadership and educators should come up with solutions how to address the identified challenges in online distance teaching. These solutions can involve conducting in-depth research into digital pedagogy, disseminating knowledge about the specifics of online interactions and running professional development programs for the university teachers to enhance their performance in courses delivered online.
\end{abstract}

\section{Introduction}

In spring of 2020, the life of people around the world changed almost overnight because of the COVID-19 pandemic. There were initiated social isolation and social distancing strategies because of which 1.5 billion students and 63 million educators around the world were forced to modify their educational practices, to suspended face-to-face instruction due to social distancing requirements and make a sudden shift to online educational practices [1]. This gave a dramatic boost to 'digital transformations' [2] of higher education system that will never be the same because there seems to be 'an invisible line' separating world events before and after COVID-19 [3].

In the last two decades, there have been published lots of articles devoted to the problems of distance education, e-learning and open education. Researchers and educators developed comprehensive approaches to address the emergence of a new learning paradigm in digital society [4]: analysed the potential of introducing information and communication technologies into the university curriculums [5]; debated about the advantages and disadvantages of online learning and teaching practices [6] considered the factors that can

* Corresponding author: tmark@mail.ru 
determine the success of online educational programs [7], as well as risks posed by teachers and student.

Researchers argued that the key challenges include digital pedagogy based on the introduction of brand new teaching course design and delivery methods; a shift in communication practices from teacher-student / student-student to student- content patterns of interactions [8], and psychological readiness of major higher education actors for online learning and teaching. The use of exclusively digital technologies in teaching and learning can be fraught with the loss or degradation of basic cognitive competencies, and reduction in the quality of educational achievements [9]. The excessive emphasis on the interaction of a student with content rather than with other students and a teacher negatively affects the processes of students' socialization at the university, and does not contribute to the development of teamwork and collaboration skills that are in demand on the labour market. And finally, digital learning can manifest depersonalization of students and, as a result, a decrease in the value of the educational process and the inadequacy of evaluation procedures [10]. This fact, along with the inability of a significant part of students to allocate and plan time for independent work with educational materials, significantly reduces students' motivation for digital learning that, in turn, negatively impacts the online teaching outcomes.

Overall, unless these challenges are met, they can become serious barriers to the success of online distance education resulting in low satisfaction rates and high dropout rates due to the severance of social ties, degradation of basic cognitive competences and reduced quality of learning outcomes. Despite such a comprehensive research into the issues of online learning and teaching, hardly anyone could imagine that in 2020 millions of teachers and students around the world will have to be exposed to all these risks and challenges because of COVID-19 pandemic outbreak.

Russian universities, like universities in other countries, were forced to switch to distance education format within two last weeks of March 2020. Over $80 \%$ of all Russian higher schools and universities had moved online by March, 23 [11], and found themselves in so called 'new normality' [12] characterized by physical and social distancing, excessive learning and teaching workloads, necessity to work and study from home and violation of work-life balances. Almost overnight all prior discussions regarding pros and cons of online learning and teaching became not so relevant because virtual reality has become an indispensable part of everyone's day-to-day educational activities. This posed a great challenge to the key higher education social actors (faculty, students and university leadership) who had to quickly adjust to 'new normality' and withstand the pressure of 'forced innovation' [13] Even though the full impact of the COVID-19 pandemic on Russian higher education is still to be reflected and evaluated, but it is obvious that this pandemic has radically changed the way of learning and teaching at universities and the university will never be the same as before the pandemic.

In literature, most attention is given to students' perceptions of their online studies, concerns about the quality issues and satisfaction rates. Not so many publications highlight the experiences of teachers and challenges they were posed to, however, those that have been published show how traumatic and stressful this time was to the faculty in terms of socialpsychological and professional transformations [14]. Overall, it can be stated that educators had no choice but to adapt to the new normality and all aspects of educators' professional activities were subject to dramatic changes: course design; course delivery and assessment; research and communication patterns.

This paper aims to analyse Russian educators' and students' perceptions of online education during the pandemic. To what extent were teachers and students ready for such rapid transition to online education format? How do they evaluate the experiences gained? What challenges were they posed to? What are greatest concerns of social actors regarding the complete transition to online distance learning practices? 


\section{Materials and methods}

This article is based on the primary and secondary research findings.

The students' survey was conducted by a group of researchers of Ural State University of Economics (USUE) in the fall of $2015(\mathrm{n}=703)$ and in early $2016(\mathrm{n}=830)$. Population was made by students of Ural State University (USUE) and Ural Federal University (UFU). The questionnaire included the following sections: the use of technologies and resources, the effectiveness of online distance learning, motivation in choosing this form of study and problems encountered during the training, student-student and student-teacher interactions, students' knowledge self-assessment, students' satisfaction with the quality of education [6, 15].

In 2018, the Department of Applied Sociology (USUE) conducted a survey of the USUE teachers' opinions on open education, a representative quota sample for institutes $(n=85)$.

The article also uses secondary data obtained from the Analytical Report "Lessons from the 'Stress Test'. Universities in the context of the pandemic and after it" [11]. The Report is based on the findings of teachers' and students' surveys and interviews with teachers carried out in March-April 2020.

\section{Results and discussions}

\subsection{Educators' and students' perceptions of online distance education before COVID-19 pandemic}

In the teachers' survey conducted two years before the outbreak of the pandemic (2018), the majority of teachers stated that they were not ready for the introduction of online distance education mode. The respondents pointed out that the regulatory legal documents for the introduction of elements of online education into full-time education are not elaborated enough $(35 \%)$, there are no appropriate teaching materials $(36 \%)$, and universities lack appropriate infrastructure for shifting teaching and learning to online environment (31\%). In addition, $14.1 \%$ of teachers admitted that they did not have a sufficient level of information and communication technologies (ICT skills). According to the teachers surveyed, at the moment the online education model "has not yet been elaborated, there are many negative points in it" (39.8\%) and, moreover, $20.5 \%$ pointed out "I have a negative attitude to the idea of online education; I think it is highly likely to destroy the education system integrity." At the same time, $19.3 \%$ indicated "I generally approve this education mode as positive and progressive."

The survey findings (2018) correlate with the findings obtained from interviews with teachers of leading universities on the eve of the transition of universities to remote education mode [11]. In 2019, the overwhelming majority of teachers $(88 \%)$ perceived the online distance education quite negatively and did not consider the remote learning and teaching format as a full-fledged replacement for the traditional full-time format. They expressed great concerns regarding the rapid spread of digital technologies in higher school.

The students' survey in 2015-2016 revealed that course designers and instructors failed to utilize the enormous interactive potential of Internet-based teaching. Despite generally positive perceptions of teaching staff competences regarding distance teaching, less than $50 \%$ of students were satisfied with the emotional contact with their instructors and only $30.5 \%$ supported the statement that online distance learning promotes interactive teacher-student communication. Among the key online learning challenges students pointed out the follows: "high level of self-learning" (53.8\%); "need for self-organization" (31.1\%); "lack of emotional communication with the teacher" (31.1\%), "lack of teacher control" and "sense of 
isolation' (13.1\%). These problems highlighted the fact that many remote students lacked the appropriate qualities and skills for successful participation in distance learning programs. More importantly, the findings of the survey conducted four years before the pandemic revealed that students are not rendered appropriate psychological and educational support to ensure their satisfaction with learning outcomes. It was clear that educators need to promote digital pedagogy and learn how to organize, guide and encourage students studying at a distance.

Teachers were also critical of social interaction and communication prospects in the context of online distance education. According to the teachers' survey (2018), 36\% did not agree that their lectures should be recorded and then posted online. From $6 \%$ to $23 \%$ of respondents agreed to this, but subject to a number of conditions: with the partial preservation of 'live' lectures $(15.7 \%)$, with an increase in hours for in-person practical classes $(22.9 \%)$, for consultations (16.9), for credit events $(6 \%)$. The main drawback that teachers pointed out was the lack of real (live) contact between the teacher and the student $(89.4 \%)$.

\subsection{Educators' and students' perceptions of online distance education amid COVID-19 pandemic}

Given quite low state of readiness for online teaching prior to the pandemic, it is obvious that Russian teachers faced great challenges in the transit to online teaching and learning. Some Russian researchers report that at the start of the pandemic educators' key challenges involved their computer literacy and availability of infrastructure and technical support [16]. This might be true but the university leadership took all the necessary measures to ensure that teachers are equipped with all the necessary digital skills. These measures included setting up sites with necessary technical support information and training materials, launching onpurpose-designed webinars about the use of LMS (Learning Management Systems), etc. Due to these measures, teachers were able to upgrade their technical skills fairly quickly. Overall, the majority of Russian students give a positive evaluation of teachers' readiness for transit to online teaching and learning in the first weeks of the pandemic (57\%) [11].

What posed a real challenge to Russian educators as well as their colleagues around the world was lack of expertise essential for digital pedagogy required for teaching courses online [3]. Depending on the technology available at the university, educators conducted classes in synchronous, asynchronous and blended formats. They had to redesign and adapt their teaching materials, and arrange teaching facilities, trying to respond to students' needs. The teaching activities became extremely stressful and time consuming, the workloads increased dramatically. The problem was that a big proportion of teachers had no online teaching experience before the pandemic outbreak. Among Russian respondents 60\% teachers rarely or never have conducted lectures and seminars in a remote format or in webinar format [11]. Similar problems with digital pedagogy experience reported around $50 \%$ of educators around the world [17].

Along with difficulties in delivering classes online educators encountered problems with student engagement and concentration during classes. As for engagement, teachers experienced great difficulty maintaining the same level of student engagement as in traditional classroom environment due to the lack of face-to-face verbal and non-verbal communication that contributes to establishing a good rapport with the students' audience, relationship-building and active involvement of students into the classroom educational activities. Given these traditional tools were not available in the conditions of online teaching, over a half of teachers expressed doubts about the possibility to control student engagement in the online educational process.

These findings correlate with those obtained during students' surveys [11], when students complained that they were mainly deprived of the opportunity to discuss, cooperate and 
interact with their peers and teachers during online classes. Even though many educational institutions used videoconferencing facilities to offer courses to their students via Zoom and Microsoft Teams, students report communication and engagement problems. Three quarters of those surveyed indicated that they faced these difficulties. The most common problems students experienced during online learning include: lack of communication with groupmates (35\%); lack of face-to-face interactions and discussions with teachers (34\%); difficulty addressing teachers with a question during online classes (35\%). In addition, students reported such problems as: focus on self-studies $(29 \%)$, it is difficult to study in the home environment (28\%), it is more difficult to address a teacher with a question $(27 \%)$, a feeling of loneliness and isolation (25\%).

Overall, students used to traditional in-person learning and teaching found themselves uncomfortable in the conditions of the formalized and tightly regulated teacher-student interaction in the online environment. Dramatic changes in patterns of verbal and non-verbal communication led to severe difficulties in assimilating the educational material presented online and low satisfaction rate with quality of education and overall learning outcomes. The faculty hold a strong belief ( $90 \%$ ) that online learning and teaching cannot ensure the quality of education compared with the traditional face-to-face learning and teaching. From those who took part in the survey in $2020,60 \%$ would like to move back to the traditional teaching mode. Thus, a noticeable part of teachers is reported to have certain negative attitudes regarding online formats, which have practically not changed during their remote teaching. As for students, around a half of the respondents are sure that their learning became less effective after the shift to online distance education.

In literature, there can be found ample evidence that problems faced by Russian university teachers are not unique in their nature. Researchers and educators from around the world report similar experiences and dramatic impacts of the forced transition to online distance learning on educational practices. It would be fair to say, that this unique exposure to 'emergency remote teaching' [18] contributed to much better overall understanding of the toolkit educators need to deliver teaching online effectively. Like in case with Russian university teachers, educators from other countries identified a deep competence gap in digital skills and digital pedagogy [19], as well as interaction modes [20].

Teaching belongs to the group of 'communicative occupations', in which the performance of professional functions is not possible without the effective use of communication, since it acts as the main means of professional activities. There have always been high professional requirements for university teachers in terms of their ability to establish and maintain relationships with students, understand their psychological characteristics, render support and encourage students' motivation to achieve learning outcomes. In addition to effective communication, teacher's public speaking skills and the ability to the audience attention have also been of paramount importance in the traditional classroom settings. The teaching experience gained throughout the academic year of 2020 emphasized how essential the teacher's role is not only in transmitting knowledge but also in supporting students and attending to their needs.

\section{Conclusion}

In conclusion, we all have gained a unique, once-in-a-lifetime experience when all higher education institutions went online within two weeks. The profound research into the experience of those who were directly involved into these processes is still ahead, because the pandemic is not over and we are still part of on-going digital transformations.

What can be said right now is that university teachers and students overall managed to fit rapid curriculum transformations to the extent that was acceptable in these emergency conditions. Yet, we identified concerns that need to be resolved for further consistent 
development of online distance education. These concerns are brought about by the educators' and students readiness for online distance learning and their attitudes to online educational practices, as well as the lack of expertise essential for digital pedagogy and appropriate interaction practices. Now, the university community does realize that true online education requires much more than just moving the curriculum online. Given many familiar educational practices turned out to be less effective online than offline, the transition to online education calls for the use of a different toolkit of teaching, interaction and communication methods.

Higher education stakeholders should come up with solutions how to address the identified challenges in online distance education. These solutions can involve conducting in-depth research into digital pedagogy, disseminating knowledge about the specifics of online interactions and running professional development programs for the university teachers to enhance their performance in courses delivered online.

\section{References}

1. World Bank Education and COVID-19, https://www.worldbank.org/en/data/interactive/2020/03/24/world-bank-education-andcovid-19

2. V. Laterza, C. E. Tømte, R. T. Pinheiro, Nord. J. Digit. Lit., 15, 225 (2020)

3. S. Bhagat, D. J. Kim, Inf. Syst. Manag., 37, 366 (2020)

4. T. Anderson, P. Rivera-Vargas, Digit. Educ. Rev., 37, 208 (2020)

5. G. Dhanarajan, Open Learn., 16, 61 (2001)

6. E. N. Zaborova, I. G. Glazkova, T. L. Markova, Sociol. Stud., 2, 131 (2017)

7. P. Rovai, J. R. Downey, Internet High Educ., 13, 141 (2020)

8. M. Moore, W. Anderson, Handbook of Distance Education (Lawrence Erlbaum Associates, Mahwah, 2003)

9. N. B. Strekalova, Bulletin of Samara University History, Pedagogy, Philology, 25, 84 (2019)

10. E. V. Borisova, Human Capital, 3, 104 (2020)

11. V. N. Falkov, Lessons from the 'Stress Test'. Universities in the context of the pandemic and after it (Higher School of Economics, Moscow, 2020)

12. M. Tesar, Policy Futures Educ., 18, 556 (2020)

13. B. Yang, C. Huang, Stud. High. Educ., 46, 121 (2020)

14. H. de Boer, Stud. High. Educ., 46, 96 (2020)

15. T. Markova, I. Glazkova, E. Zaborova, Procedia Soc. Behav. Sci., 237, 685 (2017)

16. N. Almazova, E. Krylova, A. Rubtsova, M. Odinokaya, Educ. Sci., 10, 368 (2020)

17. D. Lederman, Inside Higher Ed (2020), https://www.insidehighered.com/digitallearning/article/2020/04/22/how-professors-changed-their-teaching-springs-shiftremote

18. A. O. Mohmmed, B. A. Khidhir, A. Nazeer, V. J. Vijayan, Innov. Infrastruct. Solut., 5, $1(2020)$

19. F. J. Garcia Penalvo, A. Corell, Campus Virtuales, 9, 83 (2020)

20. M. J. Sá, S. Serpa, Sustainability, 12, 8525 (2020) 